\title{
Nanomaterials Meet Li-ion Batteries
}

\author{
Nam Hee Kwon*, Jean-Pierre Brog, Sivarajakumar Maharajan, Aurélien Crochet, \\ and Katharina M. Fromm*
}

\begin{abstract}
Li-ion batteries are used in many applications in everyday life: cell phones, laser pointers, laptops, cordless drillers or saws, bikes and even cars. Yet, there is room for improvement in order to make the batteries smaller and last longer. The Fromm group contributes to this research focusing mainly on nanoscale lithium ion cathode materials. This contribution gives an overview over our current activities in the field of batteries. After an introduction on the nano-materials of $\mathrm{LiCoO}_{2}$ and $\mathrm{LiMnPO}_{4}$, the studies of our cathode composition and preparation will be presented.
\end{abstract}

Keywords: Cathode $\cdot$ Composite structure $\cdot \mathrm{Li}$-ion batteries $\cdot \mathrm{Nano}_{-\mathrm{LiCoO}_{2}} \cdot \mathrm{Nano}^{-\mathrm{LiMnPO}_{4}}$

\section{Nano-LiCoO}

Today's commercial Li-ion batteries are typically based on the layered structure of the high-temperature (HT) phase of $\mathrm{LiCoO}_{2}$ as active material in the form of a micron-sized powder, using a carbon additive as well as a binder to increase the electronic conductivity and to process the so-obtained paste into a cathode. ${ }^{[1]}$ Commercial HT-LiCoO ${ }_{2}$ is produced via a solid-state synthesis operating under oxygen at very high temperature $\left(600-900^{\circ} \mathrm{C}\right)$ and over long times (2-3 days). ${ }^{[2,3]}$ Using the precursor method, the Fromm group was able to simplify the reaction conditions and to reduce i) the production time, ii) the reaction temperature as well as iii) the grain size. Indeed, by reacting dry $\mathrm{CoCl}_{2}$ with different ratios of $\mathrm{LiOR}$ in dry $\mathrm{THF}^{2}(\mathrm{R}=\mathrm{Ph}, \mathrm{tBu}, \mathrm{Et}, \mathrm{Me})$, we were able to obtain Li-Co alkoxides and aryloxides which combined the two metal ions. Compounds such as $\left[(\text { thf })_{2} \mathrm{Li}(\mu-\mathrm{OR})_{2} \mathrm{Co}(\mu-\right.$ $\left.\mathrm{OR})_{2} \mathrm{Li}(\text { thf })_{2}\right]$ (for $\left.\mathrm{R}=\mathrm{Ph}\right)$ and $\left[(\text { thf })_{2} \mathrm{Li}(\mu-\right.$ $\left.\mathrm{OR})_{2} \mathrm{Co}(\mu \text {-OR' })_{2} \mathrm{Co}(\mu-\mathrm{OR})_{2} \mathrm{Li}(\mathrm{thf})_{2}\right]^{2}(\mathrm{R}=$ $\left.\mathrm{Ph}, \mathrm{R}^{\prime}=\mathrm{tBu}\right)$ could be identified. $\left.{ }^{4}\right]$ While the second compound has the correct stoichiometric ratio between the metal ions and solely yields HT-LiCoO 2 as combus-

${ }^{\star}$ Correspondence: Prof. Dr. K. Fromm, Dr. N. H. Kwon, Department of Chemistry

University of Fribourg

Chemin du Musée 9, CH-1700 Fribourg

E-mail: Katharina.fromm@unifr.ch,namhee.kwon@ unifr.ch tion product, the first compound yields also $\mathrm{Li}_{2} \mathrm{CO}_{3}$ upon heating in air. This byproduct can be eliminated by a short washing step with water. ${ }^{[4]}$ Optimizing the alkoxide and aryloxide ligands, it was possible to generate the desired high-temperature phase of $\mathrm{LiCoO}_{2}$ at as low as $350{ }^{\circ} \mathrm{C}$ and within two hours. The so-obtained nano-powders of different sizes, depending on the precursor and the temperature gradients used during combustion, are now being studied by us for their electrochemical performance in Swagelok and coin cells. In comparison with the commercial micron-scale material, the nano-sized $\mathrm{LiCoO}_{2}$ is expected to possess a higher Li-ion diffusivity as the grains are smaller and the Li-ions should be able to migrate in and out of the grains much easier. Therefore, the reversible capacities of nano-sized $\mathrm{LiCoO}_{2}$ are higher at high C-rates (>1 C) compared to the micron-sized $\mathrm{LiCoO}_{2} \cdot{ }^{[5,6]} \mathrm{We}$ will soon report on these results.

\section{Nano-LiMnPO}

In parallel to this research on $\mathrm{LiCoO}_{2}$, we are also developing the technology around nano-scale $\mathrm{LiMnPO}_{4}$, an olivinetype material with high structural stability. ${ }^{[7]}$ Compared to the commercially used $\mathrm{LiFePO}_{4}$, the Mn-analogue has a $20 \%$ higher energy density based on its higher potential versus $\mathrm{Li}^{+} / \mathrm{Li}$. On the other hand, it has a lower ionic and electronic conductivity resulting in a poor capacity and rate capability. ${ }^{[8]}$ One way to overcome these drawbacks is to generate nano-scale $\mathrm{LiMnPO}_{4}$ and to add conductive carbon additives. ${ }^{[9-13]}$ Indeed, smaller particles reduce the Li-ion diffusion pathway and improve hence the ionic conductivity, while carbonaceous material such as graphite or carbon black improves the electronic conductivity (Scheme 1). ${ }^{[12]}$

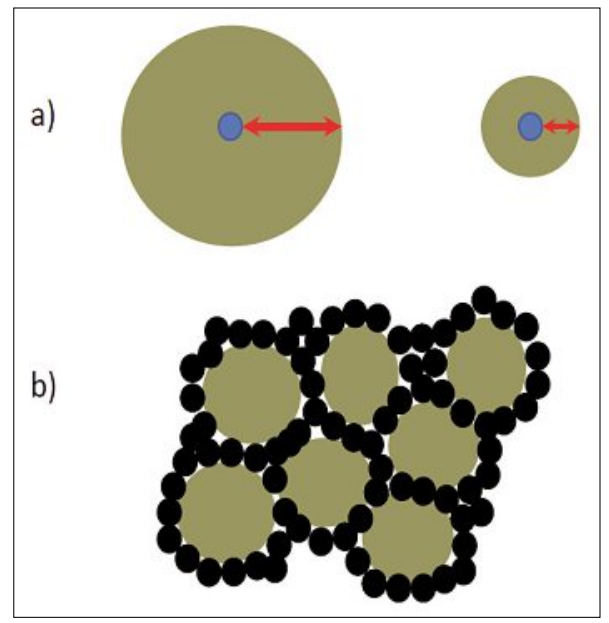

Scheme 1. a) Comparison of the maximum Li-ion (blue) diffusion pathway (red) as a function of particle size of active material (valid for $\mathrm{LiCoO}_{2}$ as well as $\mathrm{LiMnPO}_{4}$ ); b) ideal mixing of active material $\mathrm{LiMnPO}_{4}$ (olive green) with carbon black (black) as conductive additive for the improvement of electronic conductivity.

We therefore studied i) different syntheses to obtain nanoscale $\mathrm{LiMnPO}_{4}$ in order to gain control over grain size and shape, ii) the influence of the particle size, and iii) the amount of carbon additive necessary to obtain full capacity.

In a previous publication, ${ }^{[12]}$ it was shown that for sample sizes ranging from $410 \mathrm{~nm}$ to $140 \mathrm{~nm}$, the smaller the particle size, the better the reversible capacity (Fig. 1).

We therefore fine-tuned and improved the synthesis pathway using the polyol direct precipitation method (Scheme 2) in order to obtain yet smaller particles with different shapes.

In particular, we added a ligand exchange step to eliminate remaining surfactant from the surface of the particles, reducing thus the amount of remaining carbon residue after the final heating step. ${ }^{[15]}$ 


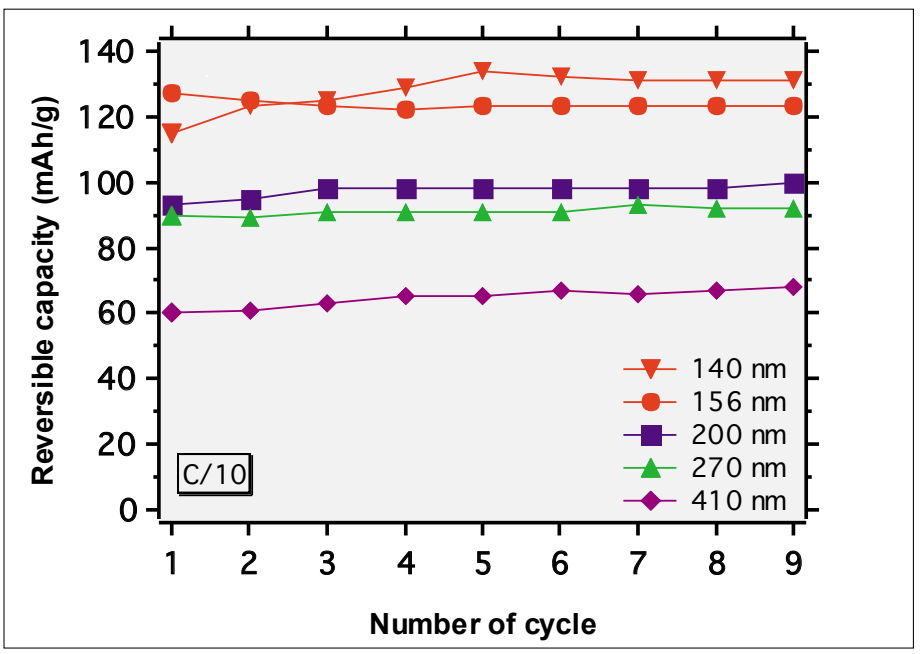

Fig. 1. The reversible capacities of $\mathrm{LiMnPO}$ consisting of different particle sizes. The smallest particle size showed the highest reversible capacity. ${ }^{[12,14]}$

Indeed, we succeeded in controlling the reaction conditions such that we could reduce the particle sizes below $30 \mathrm{~nm}$ obtaining different shapes, from spherical to rod-like (Fig. 2), and, more importantly, in very high yield. ${ }^{[15]}$

The nanoscale $\mathrm{LiMnPO}_{4}$ shown in Fig. 2 (c) was used to study the best composition of a cathode in terms of carbon additive content. The higher percentage of active material versus carbon additive required to improve the electronic conductivity, the better is the capacity per weight of an electrode. While in the literature, amounts of $20-40 \%$ of carbon are reported, we could show that as little as $10 \%$ of carbon black could give rise to the full theoretical capacity of $170 \mathrm{mAh} / \mathrm{g}$ at a charging rate of $\mathrm{C} / 40$ (Fig. 3). ${ }^{[15]}$ This brings $\mathrm{LiMnPO}_{4}$ into the game as potential commercial product for cathode materials of future Li-ion batteries.

\section{Carbon Additives and Cathode Preparation Methods}

Since many different carbon additives are available on the market, and since the generation of homogeneous nanocomposites is non-trivial, we decided to study both aspects. In a first test, four different commercial carbon additives, two graphitic and two carbon black materials, were tested under similar conditions with commercial micron-scale $\mathrm{LiCoO}_{2}{ }^{[16]}$ The plateletshaped graphite material has a lower specific surface area compared to the nanosized carbon black with spherical particles. We expected that carbon black would thus perform better than graphite, as it would mix better with the $\mathrm{LiCoO}_{2}$-particles. In parallel, we also investigated the influence of the ball-milling on the formation of the composites. ${ }^{[17]}$ For this study, we expected a longer ball-milling to lead to a more ho-
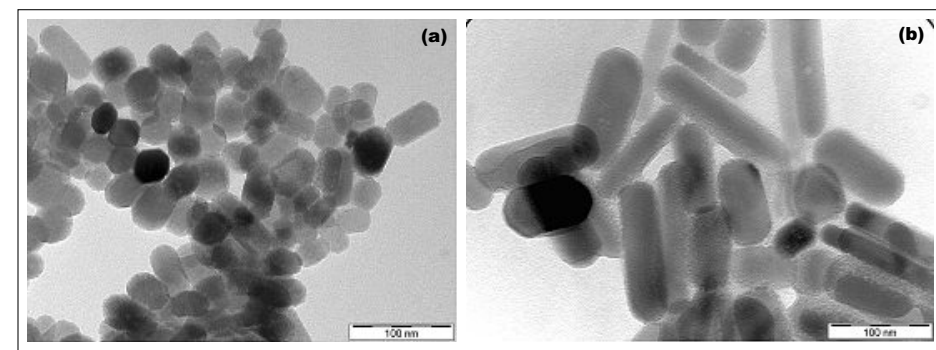

(b)
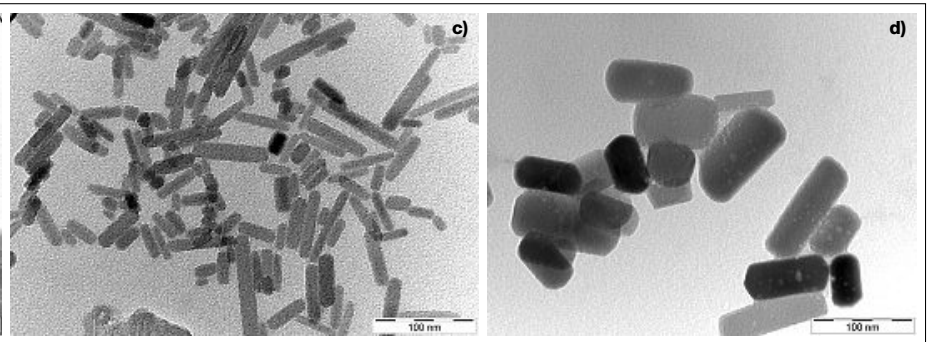

Fig. 2. TEM morphologies of $\mathrm{LiMnPO}_{4}$ controlled by the concentration of oleic acid, the reaction temperature and time. a) and b) are 9:1 and 3:1 in the molar ratio of oleic acid and precursors at $280^{\circ} \mathrm{C}$, respectively. C) is obtained at the reaction temperature of $265^{\circ} \mathrm{C}$. d) is obtained by the reaction time of $1 \mathrm{~h}$. The molar ratio of 3:1 = oleic acid and precursors in c) and d). The scale bar is $100 \mathrm{~nm}$.
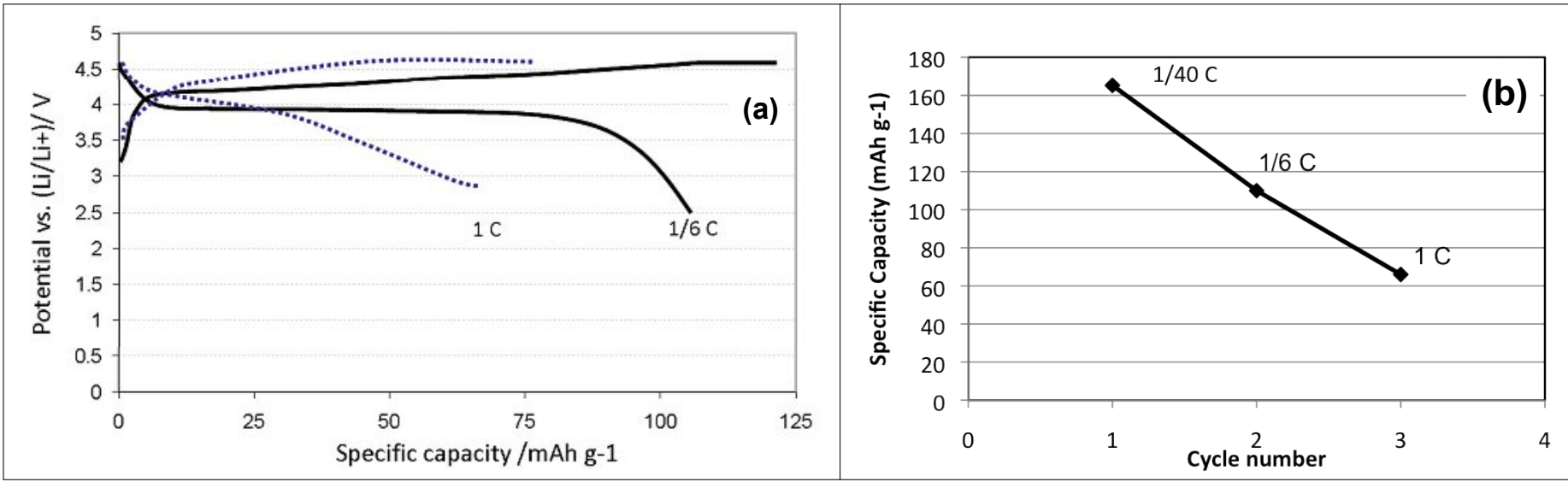

Fig. 3. a) The charge and discharge curves of $10 \mathrm{wt} \%$ carbon added nano-LiMnPO${ }_{4}$ cathode. b) The rate capability of the same cathode. 
mogenous composite and hence to better electrochemical properties.

For the generation of the composite, SEM and TEM analyses surprisingly showed that the platelet-shaped graphite assembles homogeneously with micron-sized $\mathrm{LiCoO}_{2}$ using the ball-milling method. Furthermore, a 5-min ball-milling process provided better results and smaller particles than a 30-min or 60-min ball milling or no ball-milling at all. Graphite thus turned out to provide a superior quality of the composite cathode material with a still high specific surface area. It also gives better quality cyclic voltammograms (Fig. 4, top) and leads to higher specific capacities (Fig. 4, bottom) of the $\mathrm{LiCoO}_{2}$ electrodes compared to nano-sized spherical carbon black.

The nano-sized carbon black on the other hand aggregates during the ballmilling process and forms isolated clusters for which the specific surface area is dramatically reduced. Furthermore, the thick coating of nano-carbon black on the $\mathrm{LiCoO}$, particles renders the contact with the liquid electrolyte difficult. We further assume that a long ball-milling process leads to a heating of the material and hence formation of aggregates and particle/crystallite growth. Our two studies thus lead to the conclusion that a 5-min ball milling process of micron-scale $\mathrm{LiCoO}_{2}$ with graphitic carbon provides the best composite cathodes. We are currently studying these effects also for our above-mentioned nanoscale $\mathrm{LiCoO}_{2}$ and $\mathrm{LiMnPO}_{4}$ in order to determine the best conditions for highquality electrodes.

\section{Conclusions, Ongoing Work, and Outlook}

We are now able to provide nano-scale $\mathrm{LiCoO}_{2}$ and $\mathrm{LiMnPO}_{4}$ in a multi-gram scale to partners who wish to test battery packs. Furthermore, the Fromm group has considerable expertise in the encapsulation of nanoparticles into porous inorganic shells. [18-21] We have thus started to investigate the use of encapsulated Snnanoparticles as anode material for Li-ion batteries. Within the framework of the NRP-70 of the Swiss National Science Foundation, research on the next generation batteries, such as $\mathrm{Li}$-air and $\mathrm{Li}$-water are ongoing in order to provide new membranes in collaboration with the group of H.G. Park at ETHZ, as well as electrolytes, which can also serve in classical Li-ion batteries.

Within the framework of the SCCER 'Heat and Electricity Storage', we contribute to the work package WP1 by providing our nanoscale cathode materials, assembling half cells against Li-metal and full cells against anode material provided by e.g. the group of M. Kovalenko from ETHZ. In situ and in operando studies of our composite materials are ongoing in collaboration with the group of P. Novak and C. Villevieille at the PSI. The Fromm group also collaborates with the Peter
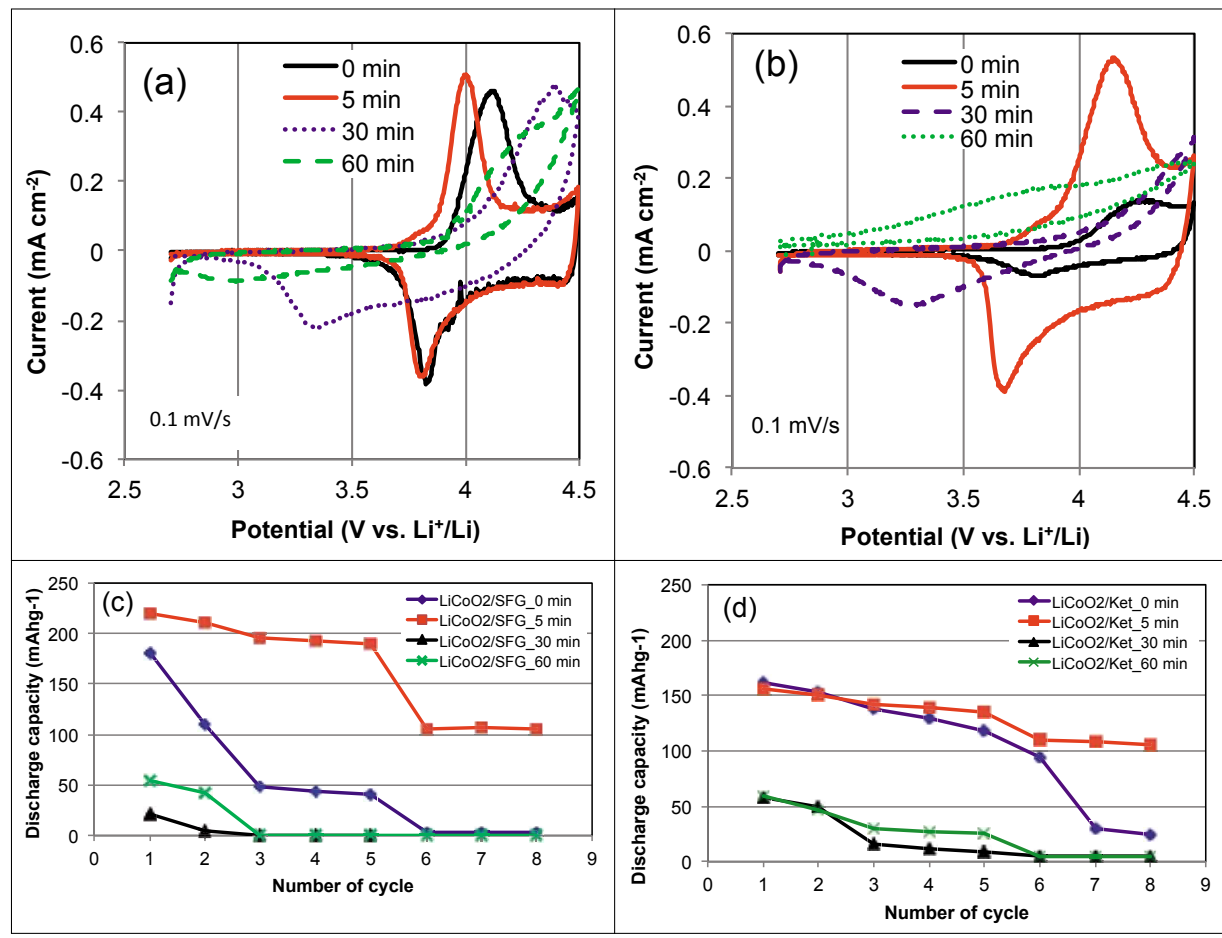

Fig. 4. Top: Cyclic voltammograms of a) $\mathrm{SFG} / \mathrm{LiCoO}_{2}$ and b) $\mathrm{Ket} / \mathrm{LiCoO}_{2}$ composite electrodes. The composites were prepared by ball milling for various milling time. ${ }^{[17]}$ Bottom: Specific capacities of $\mathrm{LiCoO}_{2}$ electrodes containing the composites with either (c) SFG or (d) Ket by various ball milling times. ${ }^{[17]}$ Reprinted from ref. [17] with permission from Elsevier.
Broekmann group of WP4 of the SCCER, and we have worked here on the synthesis and electrochemical analysis of pseudocapacitor multilayer thin films. ${ }^{[22]}$

\section{Acknowledgement}

The authors thank the Swiss National Science Foundation for generous funding (NRP-64, NRP-70), and the Swiss Center for Competence in Energy Research (SCCER) Heat and Electricity Storage in collaboration with the CTI and the University of Fribourg as well as the Fribourg Center for Nanomaterials, FriMat, for their motivating support. We also thank EKZ (Elektrizitätswerke des Kantons Zürich) for the innovation grant and Polytype SA for the collaboration.

Received: August 23, 2015

[1] K. Mizushima, P. C. Jones, P. J. Wiseman, J. B. Goodenough, Mater. Res. Bull. 1980, 15, 783.

[2] M. Yoshio, H. Tanaka, K. Tominaga, H. Noguchi, J. Power Sources 1992, 40, 347.

[3] J. N. Reimers, J. R. Dahn, J. Electrochem. Soc. 1992, 139, 2091

[4] A. Crochet, J.-P. Brog, K. M. Fromm, WO 2012000123, 2012.

[5] M. G. Kim, J. Cho, Adv. Funct. Mater. 2009, 19, 1497.

[6] A. S. Aricò, P. Bruce, B. Scrosati, J.-M. Tarascon, W. V. Schalkwijk, Nat. Mater. 2005, $4,366$.

[7] A. K. Padhi, K. S. Nanjundaswamy, J. B. Goodenough, J. Electrochem. Soc. 1997, 144, 1188.

[8] M. Yonemura, A. Yamada, Y. Takei, N Sonoyama, R. Kanno, J. Electrochem. Soc. 2004, 151, A 1352.

[9] D. Rangappa, K. Sone, Y. Zhou, T. Kudo, I. Honma, J. Mater. Chem. 2011, 21, 15813.

[10] P. Barpanda, K. Djellab, N. Recham, M. Armand, J.-M. Tarascon, J. Mater. Chem. 2011, $21,10143$.

[11] S.-M. Oh, S.-W. Oh, C.-S. Yoon, B. Scrosati, K. Amine, Y.-K. Sun, Adv. Funct. Mater. 2010, 20, 3260.

[12] N.-H. Kwon, T. Drezen, I. Exnar, I. Teerlinck, M. Isono, M. Graetzel, Elecrochem. Solid State Lett. 2006, 9, A277.

[13] C. Delacourt, P. Poizot, M. Morcrette, J. M. Tarascon, C. Masquelier, Chem. Mater. 2004, $16,93$.

[14] T. Drezen, N.-H. Kwon, P. Bowen, I. Teerlinck, M. Isono, I. Exnar, J. Power Sources 2007, 174, 949.

[15] N.-H. Kwon, K. M. Fromm, Electrochim. Acta 2012, 69, 38

[16] N. H. Kwon, Solid State Sci. 2013, 21, 59.

[17] N. H. Kwon, H. Yin, P. Brodard, C. Sugnaux, K. M. Fromm, Elecrochim. Acta 2014, 134, 215.

[18] M. Priebe, K. M. Fromm, Chem. Eur. J. 2015, $21,3854$.

[19] M. Priebe, K. M. Fromm, Part. Part. Syst. Charact. 2014, 31, 645.

[20] J. Gagnon, P. Weber, K. M. Fromm, Europ. Cells \& Materials 2011, 21, 49.

[21] J. Gagnon, M. J. D. Clift, D. Vanhecke, D. A. Kuhn, P. Weber, A. Petri-Fink, B. RothenRuthishauser, K. M. Fromm, J. Mat. Chem. B 2015, 3, 1760.

[22] V. Kaliginedi, H. Ozawa, H. Kuzume, S. Maharajan, I. V. Pobelov, N. H. Kwon, M. Mohos, P. Broekmann, K. M. Fromm, M. Haga, T. Wandlowski, Nanoscale 2015, 7, 17685. 